\title{
COUPLED SIMULATION OF GAS COOLED FAST REACTOR FUEL ASSEMBLY WITH NESTLE CODE SYSTEM
}

\author{
Filip Osusky*, Stefan Cerba, Jakub luley, Branislav Vrban, \\ JAN HASCIK
}

\author{
Institute of Nuclear and Physical Engineering, Faculty of Electrical Engineering and Information Technology, \\ Slovak University of Technology in Bratislava, Ilkovicova 3, Bratislava, Slovakia \\ * corresponding author: filip.osusky@stuba.sk
}

\begin{abstract}
The paper is focused on coupled calculation of the Gas Cooled Fast Reactor. The proper modelling of coupled neutronics and thermal-hydraulics is the corner stone for future safety assessment of the control and emergency systems. Nowadays, the system and channel thermal-hydraulic codes are accepted by the national regulatory authorities in European Union for license purposes, therefore the code NESTLE was used for the simulation. The NESTLE code is a coupled multigroup neutron diffusion code with thermal-hydraulic sub-channel code. In the paper, the validation of NESTLE code 5.2.1 installation is presented. The processing of fuel assembly homogeneous parametric cross-section library for NESTLE code simulation is made by the sequence TRITON of SCALE code package system. The simulated case in the NESTLE code is one fuel assembly of GFR 2400 concept with reflective boundary condition in radial direction and zero flux boundary condition in axial direction. The results of coupled calculation are presented and are consistent with the GFR 2400 study of the GoFastR project.
\end{abstract}

KEYworDs: Coupled calculation, fast reactor, GFR 2400, NESTLE, neutronics, thermal-hydraulics, thermal feedback, validation.

\section{INTRODUCTION}

Nowadays, the nuclear reactors are an appropriate option to decrease $\mathrm{CO}_{2}$ production as the source with high energy capacity. However, the amount of fissionable ${ }^{235} \mathrm{U}$ resources in the world are decreasing and, according to study [1], the entire conventional resources are sufficient for 240 years. Together with public pressure to reduce long-lived radiological nuclides, there is necessity to introduce new alternative energy sources, which are capable to replace commercial thermal reactors in the future. Therefore, the Generation-IV International Forum (GIF) [2] identified perspective conceptual designs of fast reactor systems including the Gas Cooled Fast Reactor (hereinafter GFR 2400). However, multiple studies raise questions about the GFR 2400 technical feasibility [3] due to safety reasons. Moreover, according to study [4] the recriticality issues may occur for fast reactor concepts and therefore the proper modelling of coupled neutronics with thermal-hydraulics is necessary to avoid these type of scenarios and for estimation of conceptual designs safety. The Institute of Nuclear and Physical Engineering (INPE) was involved in the GoFastR project [5] that was focused on development of GFR 2400 design and INPE was also participating in ALLEGRO project which is oriented in research and development of GFR 2400 demonstration unit. The paper is focused on the coupled calculation of the GFR 2400 fuel assembly by the NESTLE code system. The NESTLE code is described in section 2 together with the validation of installation. Section 3 describes the methodology of the coupled calculation and includes part about processing of appropriate parametric multigroup macroscopic cross-section library by SCALE code system, which is necessary for the calculation by the NESTLE code. The geometry and material properties of GFR 2400 are presented in section 4 The results of the SCALE and NESTLE calculations are shown in the last section 5 and are compared with the GFR 2400 reference study [6] performed during the GoFastR project [5].

\section{NESTLE CODE}

\subsection{NESTLE CODE 5.2.1 DESCRIPTION}

The main advantage of the nodal code NESTLE is the already implemented internally coupled neutronic and thermal-hydraulic iterative calculation path. The NESTLE code solves 2 or 4 group neutron diffusion equation utilizing the Nodal Expansion Method [7].

$$
\begin{array}{r}
-\bar{\nabla} \cdot D_{g} \bar{\nabla} \phi_{g}+\Sigma_{t g} \phi_{g}=\sum_{g^{\prime}=1}^{G} \Sigma_{s g g^{\prime}} \phi_{g^{\prime}}+ \\
\frac{\chi_{g}}{k} \sum_{g^{\prime}=1}^{G} \nu_{g^{\prime}} \Sigma_{f g^{\prime}} \phi_{g^{\prime}}
\end{array}
$$

where $D_{g}$ is diffusion coefficient $[\mathrm{cm}], \phi_{g}$ represents the neutron flux $\left[\mathrm{cm}^{-2} \cdot \mathrm{sec}^{-1}\right], \Sigma_{t g}$ stands for total macroscopic cross-section $\left[\mathrm{cm}^{-1}\right], \Sigma_{s g g^{\prime}}$ for in-group 
scattering cross-section $\left[\mathrm{cm}^{-1}\right], \chi_{g}$ is the fission neutrons yield, $k$ represents the multiplication factor (or fundamental eigenvalue), $\nu_{g}$ stands for average number of neutrons per fission and $\Sigma_{f g}$ represents the macroscopic fission cross-section $\left[\mathrm{cm}^{-1}\right]$. To calculate the above-mentioned diffusion equation, it is necessary to process appropriate parametric multigroup macroscopic cross-sections, according to the following equation:

$$
\begin{array}{r}
\widehat{\Sigma}_{x g}=a_{1_{x g}}+\sum_{n=1}^{2} a_{(n+1)_{x g}}\left(\Delta \varrho_{c}\right)^{n}+a_{4_{x g}} \Delta T_{c}+ \\
a_{5_{x g}} \Delta\left(T_{F_{\text {eff }}}\right)^{1 / 2}+\sum_{n=1}^{3} a_{(n+5)_{x g}}\left(\Delta N_{s p}\right)^{n}
\end{array}
$$

where $\widehat{\Sigma}_{x g}$ represents the macroscopic cross-section for particular reaction type $x$ and in the energy group $g, a_{j_{x g}}$ are expansion coefficients of modified power series, $\Delta \varrho_{c}$ is the deviation from the reference coolant density $\left[\mathrm{g} \cdot \mathrm{cm}^{-3}\right], \Delta T_{c}$ stands for deviation from the reference coolant temperature $\left[{ }^{\circ} \mathrm{F}\right], \Delta\left(T_{F_{\text {eff }}}\right)^{1 / 2}$ is the change in the square root of the effective fuel temperature in $\left[{ }^{\circ} \mathrm{F}\right]$ from the reference condition and $\Delta N_{s p}$ represents the deviation from the reference soluble poison concentration $\left[\mathrm{cm}^{-3} \cdot 10^{-24}\right]$ [7. More details could be found also in the previous study [8].

\subsection{VALIDATION OF INSTALLATION}

The first version of the NESTLE code was developed at North Carolina State University beginning in the late 1980's and the latest version of the NESTLE code 5.2.1, which is available at NEA data bank 9, was made in 2003. The license of newer developer version of the NESTLE code was not obtained by the INPE and therefore the whole calculation presented in the paper was performed on the version 5.2.1. The NESTLE code 5.2.1 was tested for Sun computers with AIX operating system based on PowerPC (PPC) processor architecture with XLF Fortran 77 compiler in 2004. Therefore, the correct installation was difficult and the virtualization of PPC architecture (on Ubuntu system 14.04.5 [10]) was necessary to perform for the successful NESTLE compilation by an updated version of XL Fortran compiler (v. 15.1.5) [1]. The NESTLE calculation is a little bit inconvenient on virtualized PPC machine due to the more than 2 orders of magnitude higher computational time. Based on the successful installation, the original code was slightly modified to comply with GFORTRAN compiler, which is available on multiple architecture platforms. The results of the validation of installation by the benchmarks included in the installation package of the NESTLE code are shown in Table 1 for the version compiled by Gfortran compiler on Ubuntu system 14.04.5 with amd64 architecture.
The results shown in Table 1 are identical for the platforms with different architecture. The difference in results of $k_{e f f}$ is less than 1 pcm for almost all cases. The deviation of the calculated coolant and fuel temperatures from the benchmark values is insignificant (less than $10^{-1}{ }^{\circ} \mathrm{F}$ ). However, the calculated results of test case number 10 achieves higher deviation from the benchmark. The testcase was prepared for calculation of the boron acid concentration in the different fuel cycles of the core and obviously, at the end of the cycle (EOC), the boron concentration should be equal to 0 . The calculated boron concentration in testcase number 10 is 1.7637 ppm (parts per million) and this difference should be discussed with the developer team in Tennessee in the future. The next section describes the calculation process and the processing of macroscopic cross-section library for NESTLE code.

\section{Calculation methodology}

Calculation scheme is presented in Fig. 1. TRITON sequence of the SCALE code system [12] is used to process appropriate parametric homogenized multigroup macroscopic cross-section library for the NESTLE code. The modelled states of the nuclear system, referred as branches, are describing the deviation from the reference state of the nuclear system according to Eq. 2 (i.e. difference in coolant density, coolant temperature and square root of effective fuel temperature for the case of GFR 2400). The above mentioned branches estimate the response of the nuclear system induced by the change of thermal-hydraulic parameters in the system.

The TRITON sequence calls the deterministic multigroup code NEWT, which estimates the neutron flux in the investigated system and process homogenized collapsed and weighted macroscopic cross-sections according to the calculated flux. A simple script was developed at INPE to prepare appropriate approximations for NESTLE code according to the provided cross-section library made by the TRITON sequence. Initially, the NESTLE code calculates the neutron flux distribution in the system. According to the calculated fission reaction rates, the thermal-hydraulic sub-channel calculation estimates the temperature distribution and density of the coolant in the system. According to these parameters, the macroscopic crosssection library is updated for next iteration step of the neutronic calculation within the NESTLE code. This process repeats until the calculation reaches the initial stopping criteria of the calculation. If the convergence of the solution is not achieved, it is necessary to update the input data and the conditions for both SCALE and NESTLE calculations. The next section describes the investigated case, which is the fuel assembly based on the GFR 2400 model. 


\begin{tabular}{llllll}
\hline $\begin{array}{l}\text { Test case } \\
\text { number }\end{array}$ & $\begin{array}{l}\text { Calculated } \\
\text { value of } k_{\text {eff }}\end{array}$ & $\begin{array}{l}\text { Benchmark } \\
\text { value of } k_{\text {eff }}\end{array}$ & $\begin{array}{l}\text { Test case } \\
\text { number }\end{array}$ & $\begin{array}{l}\text { Calculated } \\
\text { value of } k_{\text {eff }}\end{array}$ & $\begin{array}{l}\text { Benchmark } \\
\text { value of } k_{\text {eff }}\end{array}$ \\
\hline 1 & 1.000366 & 1.000364 & 14 & 1.000246 & 1.000245 \\
\hline 2 & 1.000364 & 1.000364 & 15 & 0.989215 & 0.989215 \\
\hline 3 & 1.000365 & 1.000356 & 16 & 1.000004 & 1.000000 \\
\hline 4 & 0.999968 & 0.999968 & 17 & 1.006454 & 1.006454 \\
\hline 5 & 1.000365 & 1.000363 & 18 & 1.009920 & 1.009920 \\
\hline 6 & 1.122087 & 1.122004 & 19 & 1.011475 & 1.011475 \\
\hline 7 & 1.121459 & 1.121373 & 20 & 0.977857 & 0.977858 \\
\hline 8 & 1.121039 & 1.121117 & 21 & 1.005640 & 1.005640 \\
\hline 10 & 1.200129 & 1.200129 & 22 & 0.999981 & 0.999982 \\
\hline 11 & 0.999902 & 1.000088 & 23 & 0.999936 & 0.999936 \\
\hline 12 & 0.979755 & 0.979755 & 24 & 0.999997 & 0.999997 \\
\hline & 0.989589 & 0.989589 & 25 & 0.999993 & 0.999992 \\
\hline
\end{tabular}

TABLE 1. Validation of the NESTLE code installation compiled by Gfortran compiler.

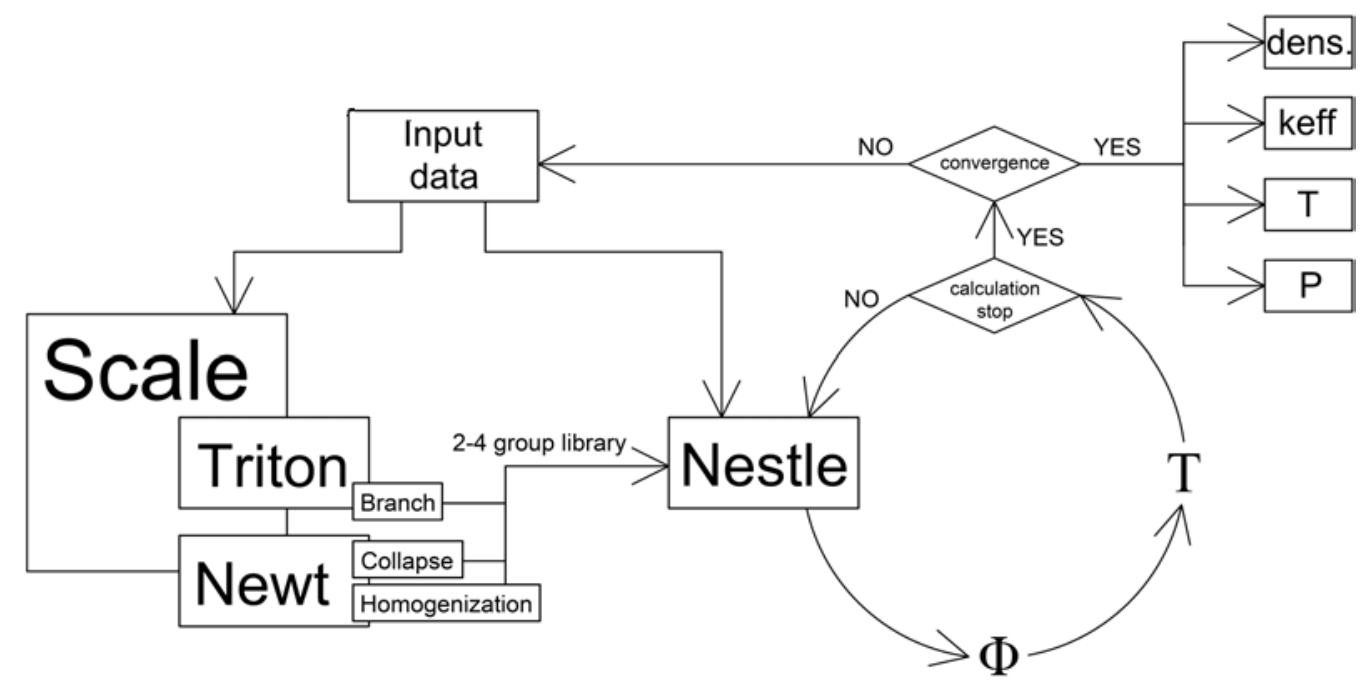

Figure 1. Calculation iteration scheme of the simulation.

\section{Description of investigated CASE}

The current experience of the Gas Cooled Reactor Technology has more than 1000 reactor years of gas thermal reactor operation in Europe [13]. Moreover, Slovakia operated the Gas Cooled Thermal Reactor A1 until mid-1980's and is one of the possible countries to build the GFR 2400 demonstration unit (referred as ALLEGRO). Therefore, the research institutes in Slovakia are involved in the research and development of Gas Cooled Fast Reactor Technology and the paper focuses on GFR 2400 concept. The power of the GFR 2400 reactor concept is $2400 \mathrm{MW}_{\mathrm{th}}$ and the planned efficiency of the indirect Brayton cycle is $45 \%$. The used coolant is helium at $7 \mathrm{MPa}$ pressure and the heat transfer is provided by three blowers with intermediate heat exchangers. The mass flow rate of the coolant inside of the fuel assemblies is $1213 \mathrm{~kg} \cdot \mathrm{s}^{-1}$ and the bypass flow rate of the coolant between the fuel assemblies is $60 \mathrm{~kg} \cdot \mathrm{s}^{-1}$. The high coolant volume fraction is characteristic for this concept (43 $\mathrm{V} / \mathrm{V}_{\text {tot }} \%$ ). The basic thermal-hydraulic parameters are shown in Table 2 and these parameters are described in more detail in previous studies [8, 14, and are accompanied with the material composition.

The cross sectional view of the GFR 2400 core is shown in Fig. 2 The chosen fuel material is uranium and plutonium carbide (hereinafter U-PuC) and one from the U-PuC benefits are appropriate thermal properties for the cores with high temperature gradient, such as GFR 2400. The core is mixed from two zones with different enrichment: the inner core, with lower 


\begin{tabular}{llll}
\hline Parameter & Value & Parameter & Value \\
\hline Thermal power $[\mathrm{MW}]$ & 2400 & Primary coolant & $\mathrm{He}$ \\
\hline Primary pressure $[\mathrm{MPa}]$ & 7 & Pressure drop in core $[\mathrm{MPa}]$ & 0.143 \\
\hline Mass flow rate $\left[\mathrm{kg} \cdot \mathrm{s}^{-1}\right]$ & 1213 & Bypass flow rate $\left[\mathrm{kg} \cdot \mathrm{s}^{-1}\right]$ & 60 \\
\hline Core inlet temp. $\left[{ }^{\circ} \mathrm{C}\right]$ & 400 & Core outlet temp. $\left[{ }^{\circ} \mathrm{C}\right]$ & 780 \\
\hline
\end{tabular}

TABLE 2. Basic thermal-hydraulic parameters [15].

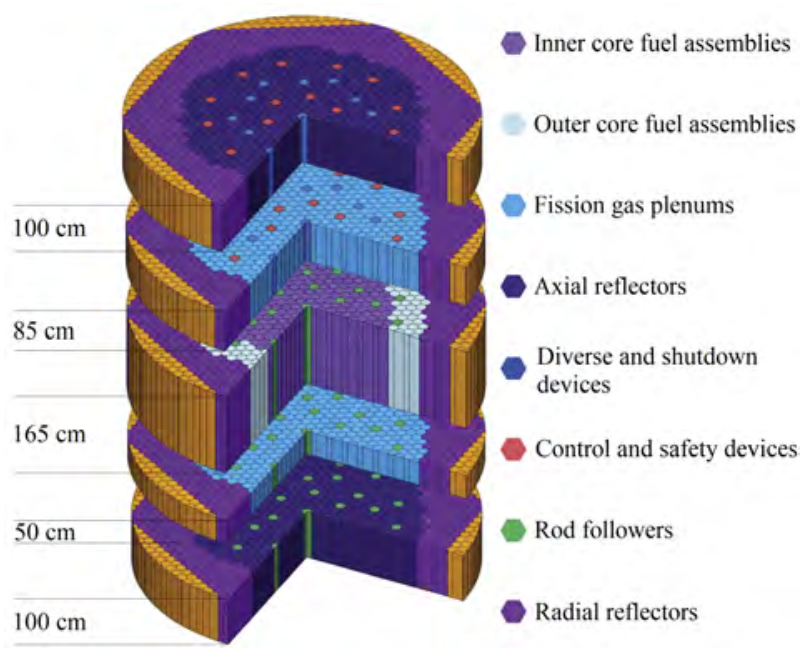

Figure 2. Cross sectional view of the GFR 2400 core 15 .

volumetric enrichment of $\mathrm{PuC} 14.12 \%$, and the outer core, with higher volumetric enrichment of $\mathrm{PuC}$ of $17.65 \%$.

The purpose of two fuel zones with different enrichment is to achieve uniformly distributed neutron flux in radial direction of the core. However, the calculation will be performed with arithmetic average volumetric enrichment of Plutonium isotopes $15.84 \%$ in the carbide fuel (Table 3).

The cross sectional view of the fuel pin is shown in Fig. 3. The middle part in the Fig. 3. represents the cut of U-PuC fuel pellet. The gap between the fuel pellet and internal liner of cladding is filled with helium. The cladding is made from mixed structure of $\mathrm{SiC}_{f} / \mathrm{SiC}$ and this material is chosen thanks to its stable behaviour during high temperature gradients. However, the $\mathrm{SiC}$ can be easily penetrated by fission gases and therefore, the special internal liner was introduced, made in the form of W14Re. The W14Re liner improves the fission gas retention of the fuel pin and moreover, prevents the carbonization of the cladding due to fuel-cladding interaction during the fuel cycle.

The homogenization of the gap, internal liner and cladding with external liner was performed to achieve faster and stable convergence of deterministic calculation made by NEWT code during the processing of macroscopic cross-section library. The description of the homogenization process could be found in the

\begin{tabular}{ll}
\hline Fuel density $\left[\mathbf{g} \cdot \mathbf{c m}^{-3}\right]$ & $\mathbf{1 0 . 9 0 0 2}$ \\
\hline$\%_{V}$ in $\mathrm{PuC}$ & 15.84 \\
\hline$\%_{W}$ in $\mathrm{PuC}$ & 15.81 \\
\hline$\%_{V}$ in UC & 84.16 \\
\hline$\%_{W}$ in UC & 84.19 \\
\hline$\%_{W} \mathrm{Pu}-238$ & 0.4065 \\
\hline$\%_{W} \mathrm{Pu}-239$ & 8.4314 \\
\hline$\%_{W} \mathrm{Pu}-240$ & 3.8995 \\
\hline$\%_{W} \mathrm{Pu}-241$ & 1.1142 \\
\hline$\%_{W} \mathrm{Pu}-242$ & 1.0991 \\
\hline$\%_{W} \mathrm{Am}-241$ & 0.1054 \\
\hline$\%_{W} \mathrm{U}-235$ & 0.5770 \\
\hline$\%_{W} \mathrm{U}-238$ & 79.5684 \\
\hline$\%_{W} \mathrm{C}-\mathrm{nat}$ & 4.7984 \\
\hline
\end{tabular}

TABLE 3. Fuel material composition [15].

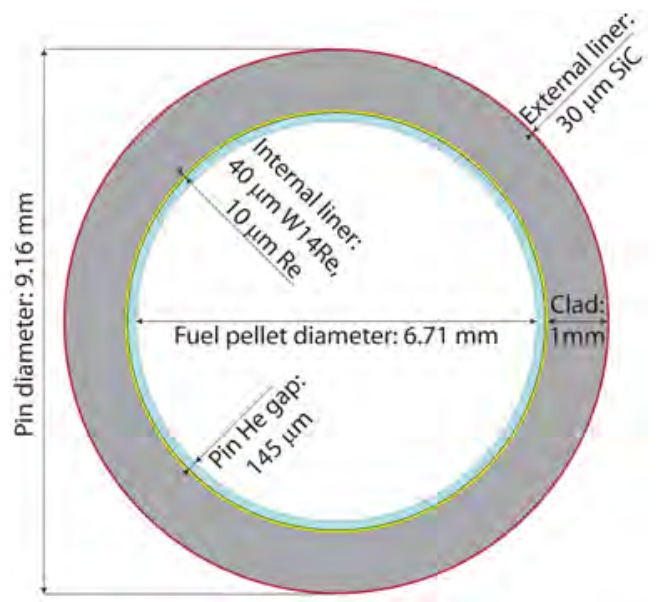

FiguRE 3. Cross sectional view of the GFR 2400 fuel pin [15]. 


\begin{tabular}{ll}
\hline $\begin{array}{l}\text { Homogenized } \\
\text { cladding }\left[\mathbf{g} \cdot \mathbf{c m}^{-3}\right]\end{array}$ & $\mathbf{2 . 9 5 7 9}$ \\
\hline$\%_{W} \mathrm{~W}-182$ & 4.9824 \\
\hline$\%_{W} \mathrm{~W}-183$ & 2.6942 \\
\hline$\%_{W} \mathrm{~W}-184$ & 5.7989 \\
\hline$\%_{W} \mathrm{~W}-186$ & 5.4380 \\
\hline$\%_{W} \mathrm{Re}-185$ & 1.9861 \\
\hline$\%_{W} \mathrm{Re}-187$ & 3.3588 \\
\hline$\%_{W} \mathrm{Si}-28$ & 48.7308 \\
\hline$\%_{W} \mathrm{Si}-29$ & 2.5611 \\
\hline$\%_{W} \mathrm{Si}-30$ & 1.7492 \\
\hline$\%_{W} \mathrm{He}-04$ & 0.0168 \\
\hline$\%_{W} \mathrm{C}-\mathrm{nat}$ & 22.6838 \\
\hline
\end{tabular}

TABLE 4. Homogenized cladding material composition [16.

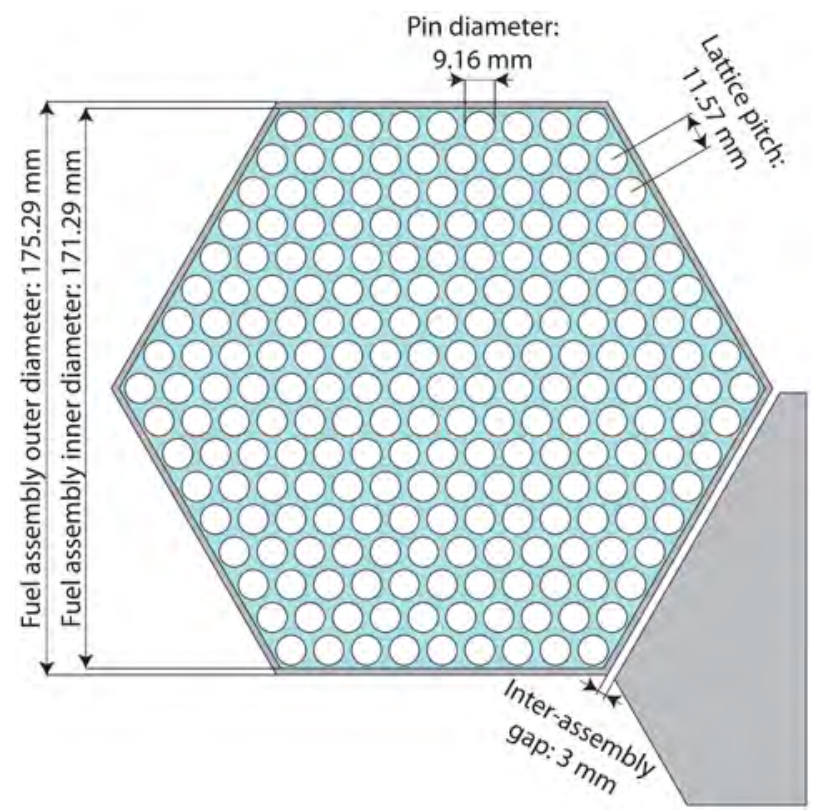

Figure 4. Cross sectional view of the GFR 2400 fuel assembly [15].

previous study [16] and the results of the fuel pin homogenization is shown in Table 4

The GFR 2400 core consists of 516 fuel assemblies and the height of the core part is $1.65 \mathrm{~m}$. Each fuel assembly consists of 217 fuel pins and the cross sectional view of the fuel assembly is shown in Fig. 4

\section{Results}

\subsection{Scale Calculation}

As mentioned above, the TRITON sequence was used for processing of the parametric macroscopic crosssection library for the NESTLE code. The mesh generated for the calculation is shown in Fig. 5 .

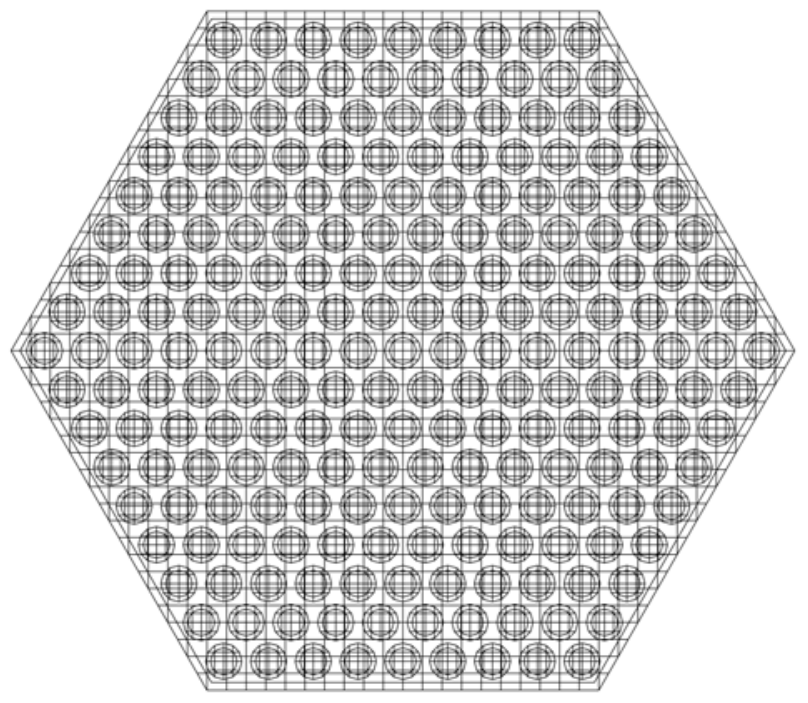

Figure 5. Mesh of the investigated case (the orthogonal mesh of the fuel pin is $4 \mathrm{x} 4$ and the mesh for whole fuel assembly is $40 \mathrm{x} 40$ ).

The standard SCALE cross-section library, referred as v7-252, was used and is based on ENDF/B-VII.1 evaluated data. The 252 neutron group library was developed to adequately capture spectral and temperature effects important for reactor systems [12] and therefore was used for the branch calculation by the TRITON sequence. White boundary condition was considered during the calculation and the convergence criterion was set to the particular mixtures and for the eigenvalue $\left(\varepsilon_{k_{e f f}}<10^{-5}\right)$. The calculations have converged for each branch calculation (inner and outer convergence was established). The reference conditions of nuclear system were the following: temperature $973.15^{\circ} \mathrm{C}$ of the fuel; temperature $673.15^{\circ} \mathrm{C}$ of the coolant; and the coolant density $4.9439 \mathrm{~kg} \cdot \mathrm{m}^{-3}$. The branch calculation was performed for the temperature range of the fuel until $1773.15^{\circ} \mathrm{C}$ with $50^{\circ} \mathrm{C}$ step. The coolant temperature range was up to $1473.15^{\circ} \mathrm{C}$ with the same step $\left(50^{\circ} \mathrm{C}\right)$. The coolant density change corresponded to the coolant temperature change, which was mentioned above. The estimated multiplication factor was 1.21519 by the deterministic NEWT calculation for the reference case. The TRITON sequence successfully process the parametric homogenized multigroup macroscopic cross-section library in raw binary data-format. Automatization script was used to prepare the approximations to the NESTLE code and the results are shown in next sub-section.

\subsection{NESTLE CALCULATION}

The boundary conditions of NESTLE calculation were set to reflective in radial direction and in axial direction to zero flux. The total flowrate of the coolant was $2.351 \mathrm{~kg} \cdot \mathrm{s}^{-1}$ for one fuel assembly and the reference power generation was $367.352 \mathrm{MW} \cdot \mathrm{m}^{-3}$ for the fuel. The fuel assembly results of the NESTLE calculation are compared with results of the previous studies [8, 14] and with the reference GFR 2400 


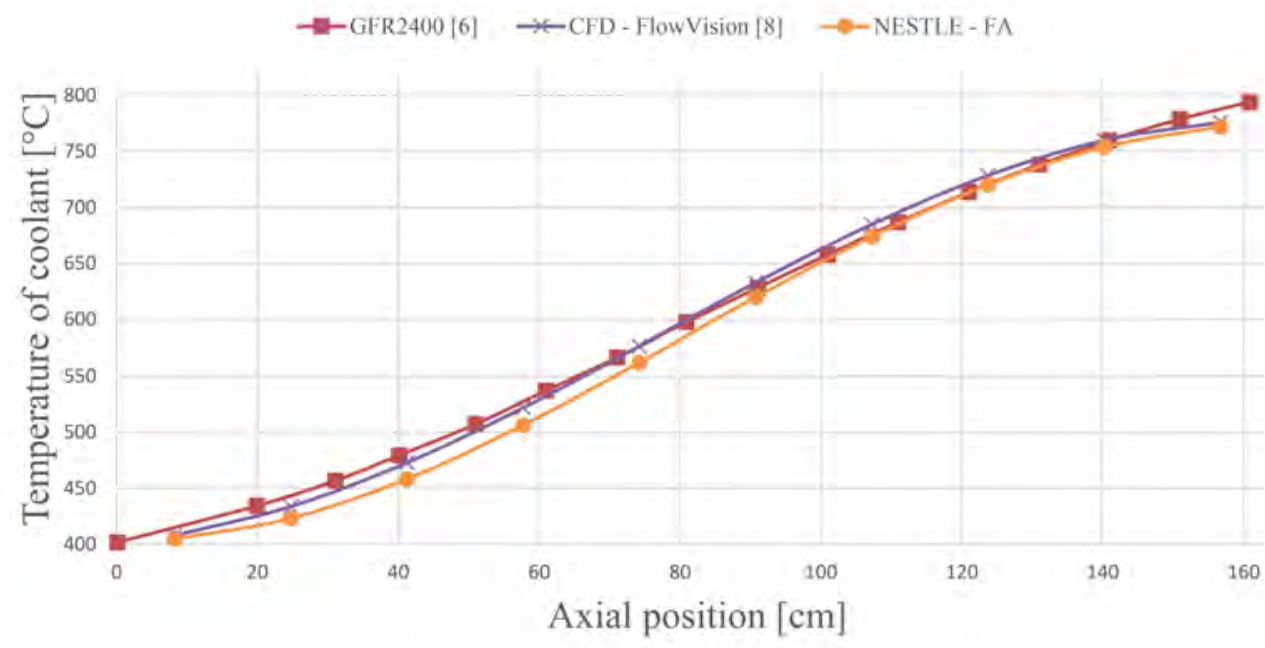

FiguRE 6. Results of the coolant axial temperature distribution.

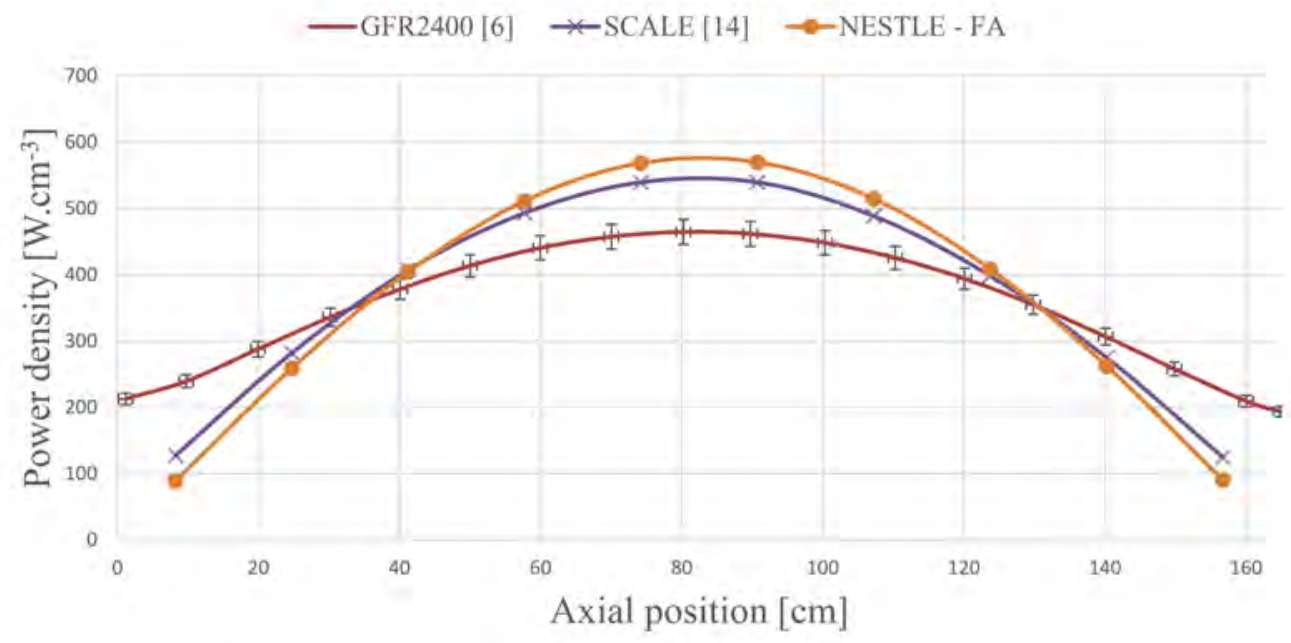

FiguRE 7. Results of axial power distribution.

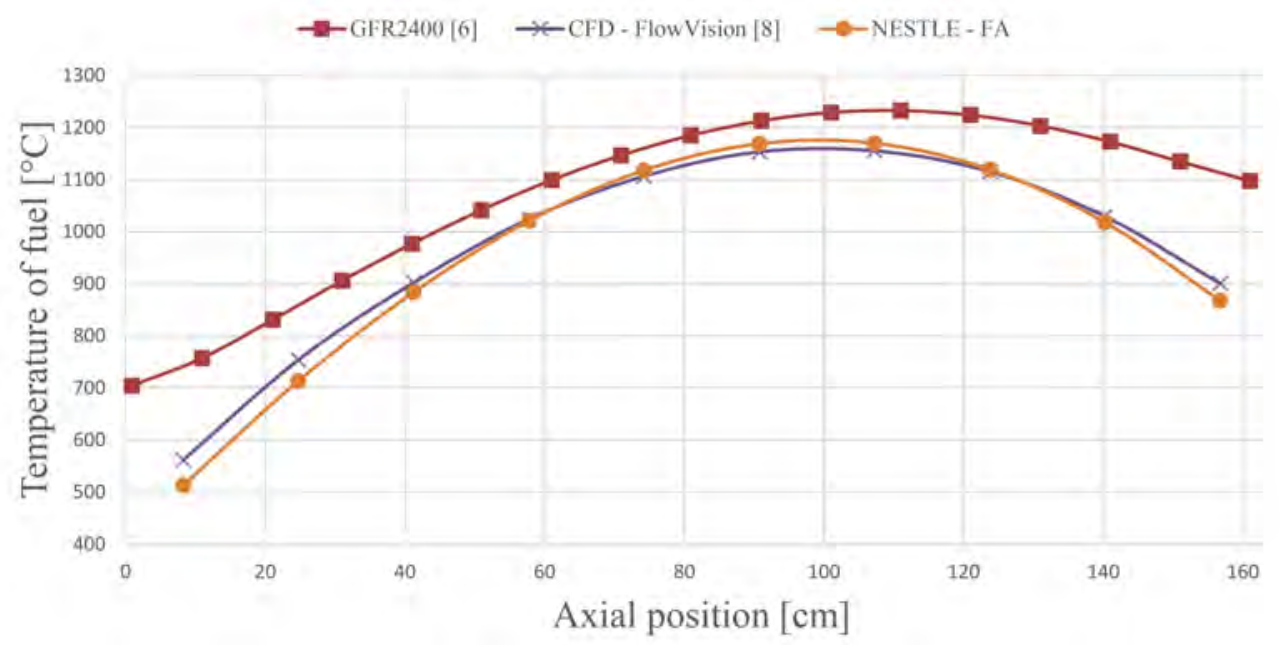

Figure 8. Results of the fuel axial temperature distribution. 
study [6]. In Fig. 6] the results of axial coolant temperature distribution are compared between the NESTLE calculation, CFD calculation made by the FlowVision code [8, 17] and between the GFR 2400 study [6]. The NESTLE calculation results show lower temperatures in the axial direction of the core than the results obtained by the CFD simulation and GFR 2400 study. In case of the CFD simulation and the GFR 2400 study, the modelled case was one pin with periodical/symmetrical boundary condition, which led to smaller cross-sectional area where the coolant flows (the cross sectional area is approximately $108.57 \mathrm{~cm}^{2}$ ) than in the case of one full fuel assembly $\left(111.09 \mathrm{~cm}^{2}\right)$. Therefore, the effectiveness of the heat removal is higher in the NESTLE calculation case, what resulted in lower temperature at the outlet, compared to the CFD simulation and the GFR 2400 study.

Results of the axial power distribution are compared in Fig. 7. The SCALE KENO VI three-dimensional calculation was performed in the previous study [14]. The SCALE model was divided into 10 zones in axial direction and the model was externally coupled with CFD FlowVision calculation. The standard SCALE cross-section library, referred as v7-238, was used in this case and is based on ENDF/B-VII.0 evaluated data. The investigated case of the SCALE-FlowVision calculation was one fuel pin with reflective boundary condition in radial direction (symmetrical boundary condition in the case of CFD simulation) and zero flux boundary condition in axial direction (pressure outlet in the case of CFD simulation). Neutronic material parameters of each zone were directly influenced by the CFD simulation. The axial reflectors below and above the core were not considered for the NESTLE calculation and for the SCALE KENO VI calculation. Therefore, the results of the simulated cases made by NESTLE and SCALE codes (Fig. 7) are not consistent with GFR 2400 study [6], where the axial reflectors were considered. The application of the axial reflectors results in the higher fission reaction rate in the axial boundary regions than for the case without application of the axial reflectors.

The results of axial fuel temperature are shown in Fig. 8 and are reflecting the calculated axial power distribution. There is good agreement of the calculated cases by NESTLE and CFD simulations.

An additional simulation was performed by the NEWT code, where the temperatures and densities were averaged, according to the performed NESTLE calculation. The result of the multiplication factor was 1.21401. The calculated multiplication factor of NESTLE code was 1.19661 and the difference from the NEWT simulation could have been caused by different approach of the deterministic-transport (typical for the NEWT code) and nodal-diffusion calculation (typical for the NESTLE code) codes.

\section{Conclusion}

The validation of the NESTLE code system installation is described in the paper. The results of the test cases were consistent with the benchmark results except one. In the test case number 10, the calculated boron acid concentration at the end of the fuel cycle was not equal to 0 , what resulted in the bias of the multiplication factor for this test case. This behaviour will be discussed in the future with the developer team in Tennessee. The coupled simulation of the GFR 2400 fuel assembly was performed by the NESTLE code and was compared with previous studies and with the reference GFR 2400 study from the GoFastR project. The results made by the NESTLE code are in good agreement with CFD simulations made by the FlowVision code. The axial reflectors above and below the core were not considered in the NESTLE simulation and this modelling approach resulted in the decrease of the power at the top and the bottom of the fuel assembly in comparison with GFR 2400 study, where these reflectors were included in the model. The technical feasibility of the GFR 2400 design raises questions and therefore the future activities with benchmarking are needed for this concept. The main reason is that the material composition of the design is quite unique and the appropriate benchmark does not exist for the GFR 2400 core.

\section{ACKNOWLEDGEMENTS}

This work was financially supported by STU Grant scheme for Support of Young Researchers HOPONE No. 1323.

\section{REFERENCES}

[1] Nuclear Energy Agency and the International Atomic Energy Agency. Uranium 2016: Resources, Production and Demand, 2016. https://www .oecd-nea.org/ndd/ pubs/2016/7301-uranium-2016.pdf.

[2] T. Abram. Generation-IV nuclear power: A review of the state of the science. Energy Policy 36:4323-4330, 2008 .

[3] G. Locatelli. Generation IV nuclear reactors: Current status and future prospects. Energy Policy 61:1503-1520, 2013.

[4] H. Ninokata. A study on recriticality characteristics of fast reactors in pursuit of recriticality-accident-free concepts. Progress in Nuclear Energy 29:387-393, 1995.

[5] European Commission. GoFastR : European Gas Cooled Fast Reactor. [2017-11-30], http: //cordis.europa.eu/project/rcn/96860_en.html

[6] European Commission. GoFastR : GFR2400 core neutronics and thermal-hydraulics characterization, 2012. Work Package 1.1: GFR Conceptual Design, http://www.janleenkloosterman.nl/reports/ gofastr_d1111_201203.pdf

[7] Electric Power Research Center, North Carolina State University. NESTLE Version 5.2.1: Few-Group Neutron Diffusion Equation Solver Utilizing The Nodal Expansion Method for Eigenvalue, Adjoint, Fixed-Source Steady-State and Transient Problems, 2003. 
[8] F. Osusky. Test case specifications for coupled neutronics-thermal hydraulics calculation of gas-cooled fast reactor. Journal of Physics: Conference Series 781(1):10, 2016. http:

//iopscience.iop.org/1742-6596/781/1/012038

[9] Nuclear Energy Agency. CCC-0641 NESTLE 5.2.1. [2017-11-30], http://www.oecd-nea.org/tools/ abstract/detail/ccc-0641/

[10] Ubuntu. Ubuntu-14.04.5-server-ppc64el. [2017-11-30], http:

//cdimage.ubuntu.com/releases/14.04/release/

[11] IBM. Getting Started with XL Fortran for Little Endian Distributions. Version 15.1.5.

[12] Oak Ridge National Laboratory. SCALE Code System, 2016. Version 6.2.1.

[13] R. Stainsby. Gas cooled fast reactor research in europe. Nuclear Engineering and Design 241:3481-3489, 2011.
[14] F. Osusky. Definition of the thermal-hydraulic model of the gas-cooled fast reactor, 2017. In Nuclear 2017: 10th International conference on sustainable development through nuclear research and education. Pitesti, Romania. May 24-26, 2017. Pitesti: RATEN ICN Pitesti. ISSN 2066-2955.

[15] Z. Perko. Core neutronics characterization of the gfr2400 gas cooled fast reactor. Progress in Nuclear Energy 83:460-481, 2015.

[16] F. Osusky. Macroscopic cross-section processing for nestle code system, 2017. In APCOM 2017 :

Proceedings of 23rd international conference on applied physics of condensed matter. Strbske Pleso, Slovak Republic, June 12-14, 2017. Vol. 1. Bratislava: Publisher Spektrum STU. ISBN 978-80-227-4699-1.

[17] CAPVIDIA. Flow V ision: Version 3.09.04, 2015. Installation and Setup guide. 